УДК 622.276

\title{
ВЛИЯНИЕ ПЕТРОФИЗИЧЕСКИХ ПАРАМЕТРОВ РИФОГЕННЫХ КАРБОНАТНЫХ КОЛЛЕКТОРОВ НЕФТЯНЫХ МЕСТОРОЖДЕНИЙ ТУРНЕЙСКО-ФАМЕНСКИХ ОТЛОЖЕНИЙ ВЕРХНЕГО ПРИКАМЬЯ НА ПРОДУКТИВНОСТЬ ДОБЫВАЮЩИХ СКВАЖИН
}

\section{Мартюшев Дмитрий Александрович',} martyushevd@inbox.ru

\author{
Зайцев Роман Александрович², \\ roman.zaitsev@pnn.lukoil.com
Пермский национальный исследовательский политехнический университет, Россия, 614990, г. Пермь, пр. Комсомольский, 29.
2 Филиал ООО «ЛУКОЙЛ-Инжиниринг» «ПермНИПИнефть» в г. Перми, Россия, 614000, г. Пермь, ул. Советской Армии, 29.

\begin{abstract}
Актуальность работы обусловлена тем, что большинство карбонатных залежей нефтяных месторождений Верхнего Прикамья, приуроченных к рифовым структурам, относится к коллекторам трещинно-порового типа. При разработке таких сложнопостроенных объектов продуктивность скважин зависит от раскрытости и проницаемости трещин, их относительной емкости и взаимной сообщаемости между трещинами и матрицей, от азимутального распространения естественных трещин по площади залежей. Указанные параметры и факторы по-разному проявляются на отдельных участках залежей в процессе их разработки, и в этой связи вопрос оценки и прогнозирования коэффициентов продуктивности добывающих скважин нефтяных месторождений Верхнего Прикамья является одним из актуальных и приоритетных.

Цель: по промысловым данным получить эмпирические зависимости для оперативного прогнозирования параметров естественной трещиноватости и продуктивности добывающих скважин, эксплуатирующие турнейско-фаменские отложения месторождений Верхнего Прикамья.

объекты: турнейско-фаменские карбонатные отложения месторождений Верхнего Прикамья.

Методы. В основу работы положены литературные материалы и исследования ученых в данной области. Исследования основаны на фактических промысловых материалах геофизических, гидродинамических исследований, которые проводились на нефтяных месторождениях Верхнего Прикамья; данных лабораторных исследований кернового материала и шлифов горных пород. Результаты. Определены относительная емкостная характеристика трещин, коэффициенты перетока между трещинами и матрицей и средняя раскрытость трещин, а также их динамика при снижении забойных и пластовых давлений в процессе разработки залежей. Получена система эмпирических зависимостей для оценки и прогнозирования средней раскрытости и относительной емкости трещин, коэффициентов перетока между матрицей и трещинами, а также продуктивности добывающих скважин в процессе разработки нефтяных залежей с карбонатными коллекторами.
\end{abstract}

\section{Ключевые слова:}

Литолого-фациальные зоны, карбонатные коллекторы, естественная трещиноватость, раскрытость трещин, относительная емкость трещин, продуктивность скважин

\section{Введение}

В последнее время в мире наблюдается тенденция к снижению добычи нефти из терригенных коллекторов, так как крупные месторождения в значительной мере выработали свой ресурс. Это ведет к все большему вовлечению в разработку трудноизвлекаемых запасов углеводородов, сосредоточенных преимущественно в карбонатных коллекторах.

В Пермском крае в залежах с карбонатным коллектором содержится около 60 \% общих запасов нефти. Значительная часть карбонатных коллекторов нефтяных месторождений на территории Верхнего Прикамья относится к трещинно-поровому типу. В соответствии с работами [1-4] естественный фон трещиноватости нефтяных месторождений на территории Верхнего Прикамья является более интенсивным, чем на месторождениях, расположенных в других районах Пермского края. В данной работе рассмотрены турнейскофаменские отложения (Т-Фм) Гагаринского и
Озерного месторождений, отличающиеся от других месторождений Верхнего Прикамья тем, что имеют сложное геологическое строение и характеризуются наличием четырех литолого-фациальных зон с различной степенью естественной трещиноватости и соответственно с различными фильтрационно-емкостными свойствами, обусловленными различными условиями осадконакопления. Разработка залежей со сложным строением пустотного пространства зачастую сопровождается трудностями, например, в реализации высокоэффективной системы заводнения, и, как следствие, происходит снижение пластового давления, продуктивности скважин, что ведет к неполной выработке запасов.

В целом для Т-Фм залежей Гагаринского и Озерного месторождений выделяются два типа коллекторов: один характеризуется как трещинно-поровый, обладающий в исходном состоянии открытой естественной трещиноватостью (зона верхнего тылового шлейфа - обладает лучшими 

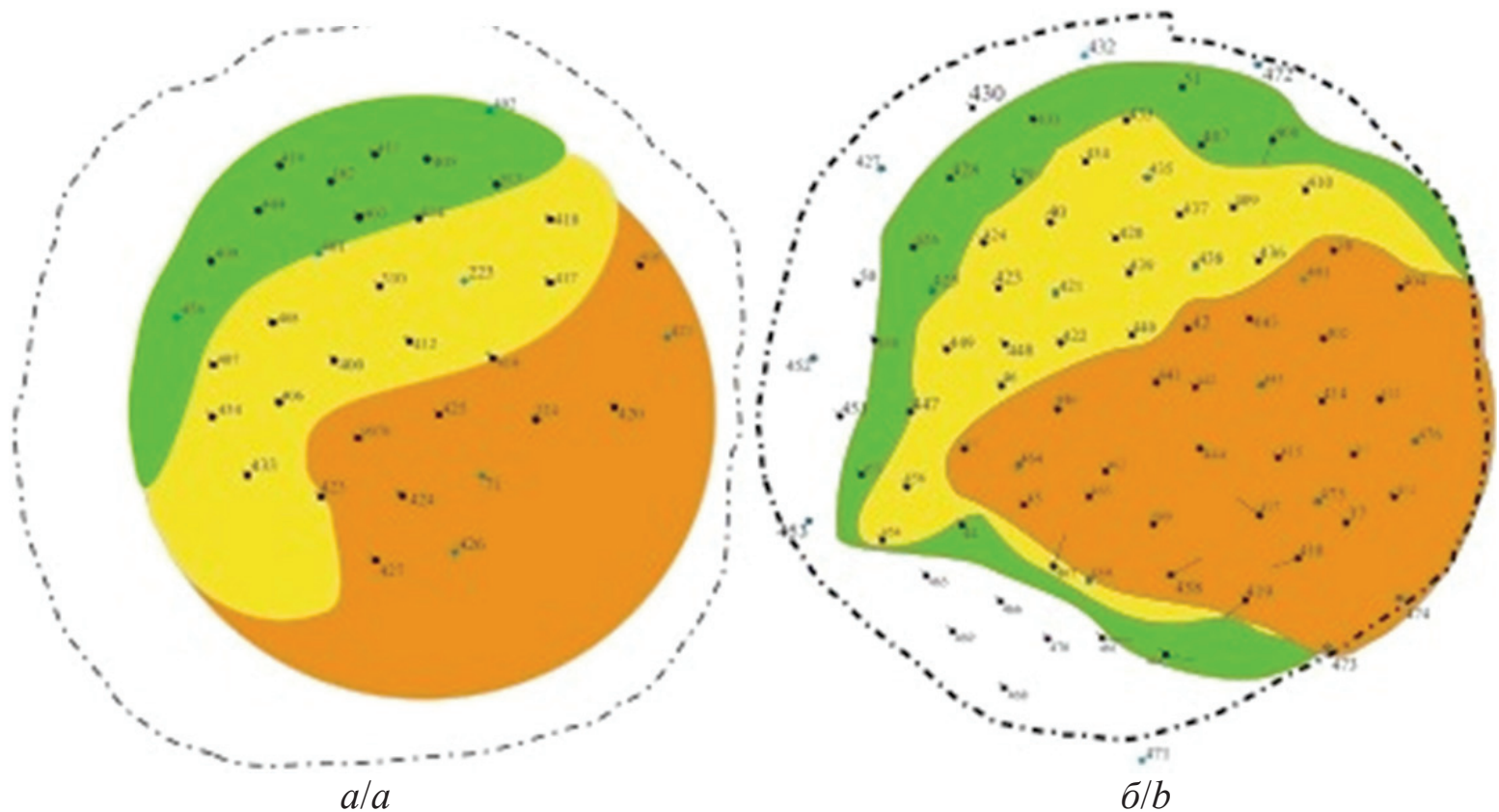

$\sigma / b$

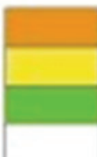

Нижний тыловой шлейф
Верхний тыловой шлейф
Биогермное ядро
Склон рифа

Условные обозначения

добывающая скважина

- нагнетательная скважина

-.-. внешний контур нефтеносности

Pис. 1. Фациальная схема турнейско-фаменского органогенного массива: а) Гагаринское месторождение; б) Озерное месторождение

Fig. 1. Facial scheme of the Tournaisian-Famennian organogenic array: a) Gagarinskoe deposit; b) Ozernoe deposit

коллекторскими свойствами), второй как трещинно-поровый, обладающий естественной трещиноватостью, частично залеченной вторичными минералами, переходящий в поровый (зоны нижнего тылового шлейфа, биогермного ядра и рифового склона). На рис. 1 представлены литолого-фациальные схемы турнейско-фаменских отложений Гагаринского и Озерного месторождений (масштаб $1: 25000)$.

\section{Исследование структуры пустотного пространства и определение параметров естественной трещиноватости}

Эффективное изучение и дальнейшая разработка карбонатных коллекторов возможны на основе качественного отбора и исследования представительного кернового материала с получением максимально полной информации о петрофизических характеристиках. Для определения структуры пустотного пространства и изменения ее по площади залежей проведена серия лабораторных экспериментов с использованием современного метода микрофокусной рентгеноскопии (томографии) (рис. 2) [5-7].

С помощью изучения кернового материала можно получить характеристики пласта только в месте его отбора, то есть в слое горных пород, непосредственно прилегающем к стенке скважины. При анализе образцов керна установлено, что средняя раскрытость трещин находится в диапазоне от

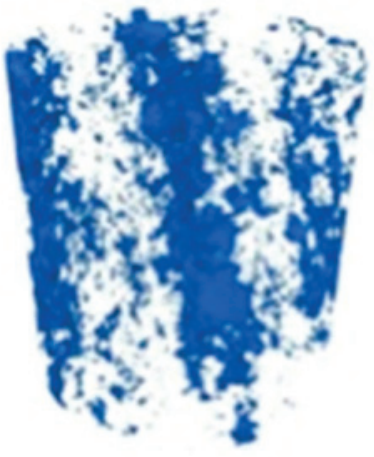

$a / a$

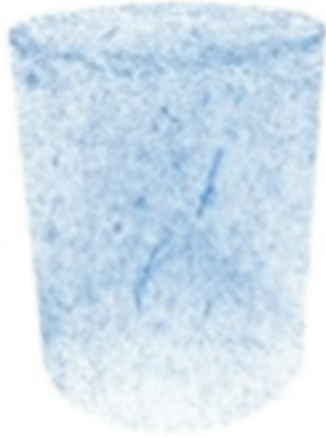

$\sigma / b$
Pис. 2. Структура пустотного пространства: а) зона верхнего тылового шлейфа, обладающая открытой естественной трещиноватостью; б) зоны биогермного ядра, нижнего тылового шлейфа и рифового склона, обладающие естественной трещиноватостью, частично залеченной вторичными минералами

Fig. 2. Structure of a void space: a) zone of the upper rear tail with open natural fractures; $b$ ) zones of the bioherm kernel, the lower rear tail and the reef slope with natural fractures, healed by secondary minerals

20 до 40 мкм, что подтверждено в работах [8, 9]. Максимальная раскрытость трещин, которая получена при исследовании керна, составляет 80 мкм, но она не является максимальной применительно ко всему массиву горных пород ввиду то- 
го, что керн с наиболее протяженными и имеющими большее раскрытие трещинами был частично разрушен в процессе бурения, а также при изготовлении образцов. При исследованиях по керновому материалу и шлифам горных пород возможно определение раскрытости естественных трещин только в начальный период эксплуатации скважин, следовательно, невозможно определить раскрытость и другие параметры естественных трещин в процессе разработки залежей.

Отмечено [10-14], что при проектировании и анализе разработки карбонатных залежей нефти наиболее важными по характеру получаемых данных являются гидродинамические исследования скважин (ГДИ). При определении фильтрационных характеристик коллекторов по данным ГДИ, основанных на изучении неустановившихся процессов фильтрации, используются результаты наблюдения движения жидкости к забою скважины в естественных пластовых условиях [15-17].

Исследования, проведенные в трещинно-поровом типе коллектора, обладающем открытой трещиноватостью, выделяются особым видом кривой восстановления давления (КВД). Кривые восстановления и падения давления, в соответствии с моделью Уоррена-Рута, графически представлены двумя параллельными линиями вместо одной как в случае порового коллектора [18-22]. Tрещинно-поровый пласт в модели Уоррена-Рута представляет собой одинаковые прямоугольные параллелепипеды (моделирование матричных блоков), которые разделены трещинами. При условии квазистационарного состояния матрица питает трещины и по трещинам жидкость фильтруется к забоям скважин. Для описания процесса в данной модели присутствуют два безразмерных параметра $\lambda$ и $\omega$, которые характеризуют взаимосвязь между матричной пустотностью и пустотностью трещиноватости. Величина $\lambda$ - интенсивность перетока жидкости между двумя областями пласта, а $\omega$ - относительная емкостная характеристика этих областей.

Эмпирические зависимости для оценки и прогнозирования параметров трещиноватости и продуктивности скважин

На рис. 3, 4 представлены графики, построенные на основании данных промысловых исследований, изменения средней раскрытости трещин и коэффициентов продуктивности при снижении забойных давлений для различных зон карбонатного коллектора с естественной трещиноватостью Гагаринского и Озерного месторождений.

Для зоны коллектора с открытой естественной трещиноватостью наблюдается наличие трех стадий изменения основных параметров трещиноватости при снижении забойного давления, которые описываются следующими уравнениями:

а) для зон с открытой естественной трещиноватостью:

$$
\begin{aligned}
& W_{\text {тек }}=\left(2,545 P_{\text {заб }} / P_{\text {пл0 }}-1,309\right) W_{\text {нач }} \\
& \text { при } 0,71 \leq P_{\text {заб }} / P_{\text {пл0 }} \leq 0,9 \text {, мкM; } \\
& W_{\text {тек }}=\left(1,108 P_{\text {заб }} / P_{\text {пл0 }}-0,262\right) W_{\text {нач }} \\
& \text { при } 0,41 \leq P_{\text {заб }} / P_{\text {пл0 }} \leq 0,7 \text {, мКМ; } \\
& W_{\text {тек }}=\left(0,620 P_{\text {заб }} / P_{\text {пл } 0}-0,032\right) W_{\text {нач }} \\
& \text { при } 0,10 \leq P_{\text {заб }} / P_{\text {пл0 }} \leq 0,4 \text {, МКм; } \\
& \omega=\left(0,533 P_{\text {заб }} / P_{\text {пл0 }}-0,133\right) W_{\text {нач }}
\end{aligned}
$$

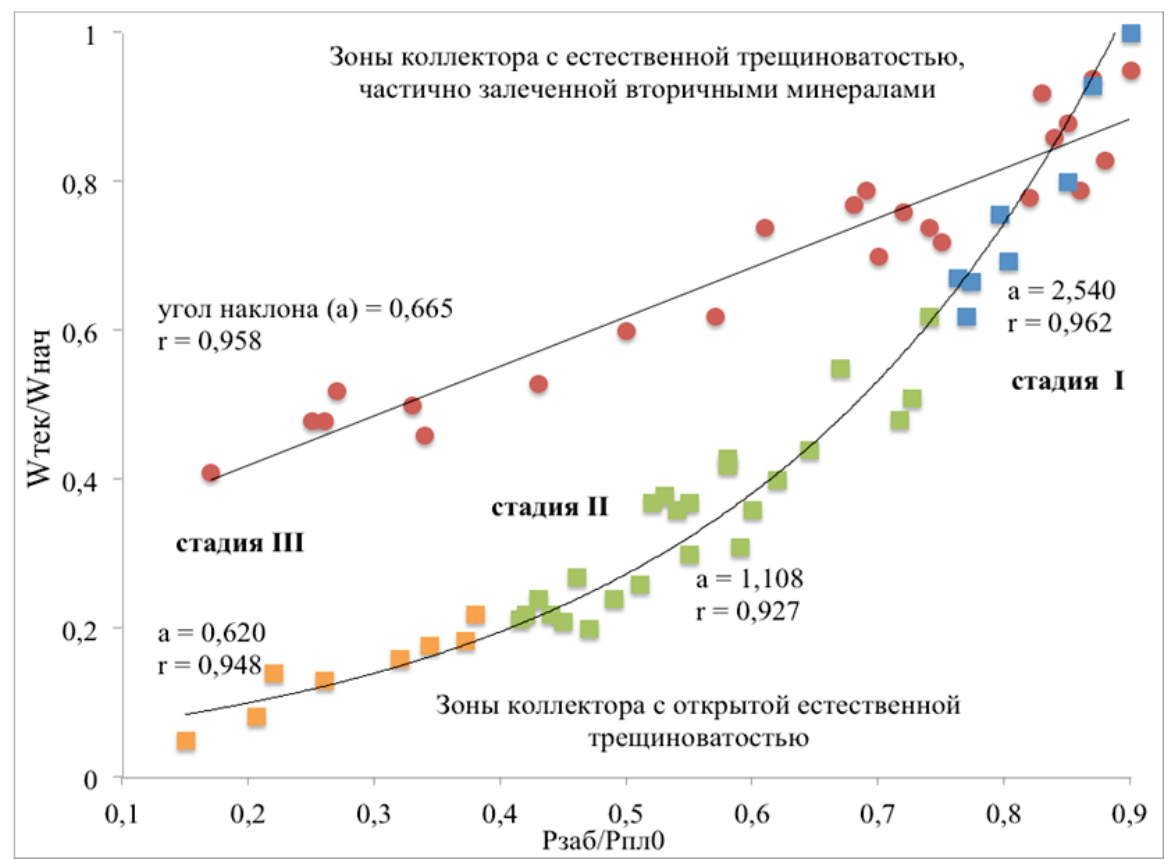

Puc. 3. Зависимость $W_{\text {тек }} / W_{\text {нач }}$ om $P_{\text {заб }} / P_{\text {пло }}$

Fig. 3. Dependence of the current openness of the fractures/initial fractures opening on Bottomhole pressure/reservoir pressure 


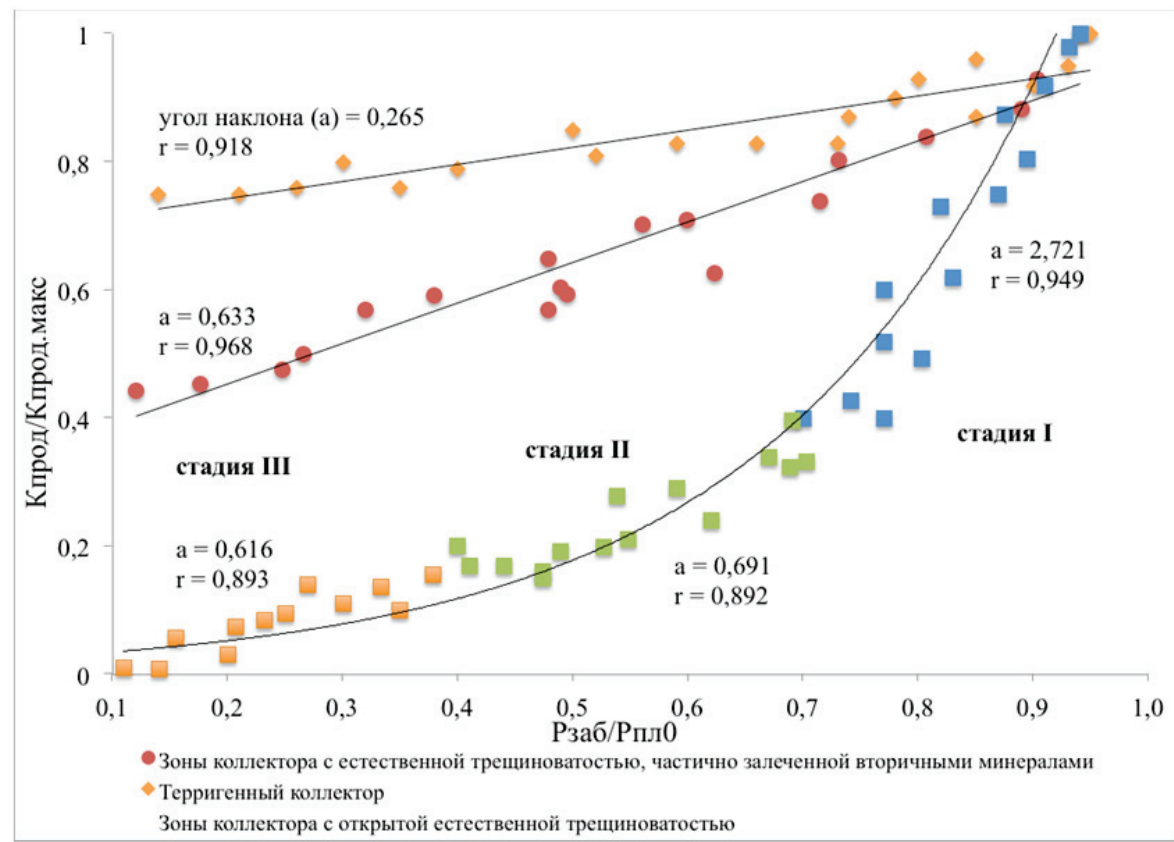

Puc. 4. Зависимость $K_{\text {прод }} / K_{\text {прод.макс }}$ от $P_{\text {заб }} / P_{\text {пло }}$ для различных зон коллекторов Гагаринского и Озерного месторождений

Fig 4. Dependence of $K_{\text {prod }} / K_{\text {prod.max }}$ on $P_{\text {bottombole }} / P_{\text {reservoir }}$ for different zones of collectors of Gagarinskoe and Ozernoe deposits

$$
\begin{aligned}
& \text { при } 0,71 \leq P_{\text {заб }} / P_{\text {пло }} \leq 0,9 \text {, мкм; } \\
& \omega=\left(0,330 P_{\text {заб }} / P_{\text {пло }}-0,017\right) W_{\text {нач }} \\
& \text { при } 0,41 \leq P_{\text {заб } /} / P_{\text {пло }} \leq 0,7, \text { мкм; } \\
& \omega=\left(0,229 P_{\text {заб }} / P_{\text {пг } 0}-0,053\right) W_{\text {нач }} \\
& \text { при } 0,10 \leq P_{\text {заб } /} / P_{\text {пло }} \leq 0,4 \text {, мкм; } \\
& \lambda=\left(2321,6 P_{\text {заб }} / P_{\text {пг } 0}-7150,7\right) \cdot 10^{-9} \\
& \text { при } 0,71 \leq P_{\text {заб }} / P_{\text {пр0 }} \leq 0,9 \text {; } \\
& \lambda=\left(4567,7 P_{\text {заб }} / P_{\text {пг } 0}-1103,5\right) \cdot 10^{-9} \\
& \text { при } 0,41 \leq P_{\text {заб }} / P_{\text {пг } 0} \leq 0,7 \text {; } \\
& \lambda=\left(3775,5 P_{\text {заб̆ }} / P_{\text {пло }}-616,1\right) \cdot 10^{-9} \\
& \text { при } 0,10 \leq P_{\text {заб }} / P_{\text {пг } 0} \leq 0,4 \text {. }
\end{aligned}
$$

б) для зон с естественной трещиноватостью, частично залеченной вторичными минералами:

$$
\begin{gathered}
W_{1}=\left(0,665 P_{1} / P_{1}-0,286\right) W_{\text {нач }} \\
\text { при } 0,71 \leq P_{\text {заб }} / P_{\text {пл } 0} \leq 0,9, \text { мКМ; } \\
\omega=\left(0,215 P_{\text {заб }} / P_{\text {пл0 }}-0,178\right) W_{\text {нач }} \\
\text { при } 0,71 \leq P_{\text {заб }} / P_{\text {пг }} \leq 0,9, \text { мКМ; } \\
\lambda=\left(3898,1 P_{\text {заб }} / P_{\text {пг } 0}-1350,0\right) \cdot 10^{-9} \\
\text { при } 0,71 \leq P_{\text {заб }} / P_{\text {пл0 }} \leq 0,9 .
\end{gathered}
$$

Начальная раскрытость трещин $W_{\text {нач }}$ по конкретной скважине определяется либо по шлифам горной породы, либо при обработке данных КВД, снятых в начальный период эксплуатации.

Для оценки и прогнозирования коэффициентов продуктивности в процессе разработки залежей получены следующие зависимости:

a) зоны, обладающие открытой естественной трещиноватостью:

$$
\begin{aligned}
& K_{\text {прод }} / K_{\text {прод.макск }}=\left(2,721 P_{\text {заб }} / P_{\text {пл0 }}-1,579\right) W_{\text {нач }} \\
& \text { при } 0,71 \leq P_{\text {заб }} / P_{\text {пл0 }} \leq 0,9 \text {, мкм; } \\
& K_{\text {прог }} / K_{\text {прог,.макс }}=\left(0,691 P_{\text {заб }} / P_{\text {пт0 }}-0,120\right) W_{\text {нач }} \\
& \text { при } 0,41 \leq P_{\text {заб }} / P_{\text {ппо }} \leq 0,7 \text {, мкм; } \\
& K_{\text {прод }} / K_{\text {прод.магсс }}=\left(0,616 P_{\text {заб } /} / P_{\text {пт0 }}-0,042\right) W_{\text {нач }} \\
& \text { при } 0,10 \leq P_{\text {заб }} / P_{\text {пл0 }} \leq 0,4 \text {, мкм. }
\end{aligned}
$$

б) зоны, обладающие естественной трещиноватостью, частично залеченной вторичными минералами:

$$
\begin{gathered}
K_{\text {прод }} / K_{\text {прод.макс }}=\left(0,633 P_{\text {заб }} / P_{\text {пл0 }}-0,327\right) W_{\text {нач }} \\
\text { при } 0,71 \leq P_{\text {заб }} / P_{\text {пло }} \leq 0,9, \text { мКм. }
\end{gathered}
$$

Из рис. 4 следует, что для зоны верхнего тылового шлейфа значительное снижение коэффициентов продуктивности происходит уже при забойных давлениях выше давления насыщения, что связанно с деформационными процессами (смыкание естественных трещин). С уменьшением забойного давления происходит смыкание естественных трещин и, вследствие этого, снижение притока в скважину. Для сохранения дебита нефти на определенном уровне для скважин, дренирующих коллекторы с естественной трещиноватостью, необходимо поддерживать (существенно не снижать) или повышать значительно сниженные забойные давления.

Из вышесказанного следует, что карбонатные залежи имеют сложную фильтрационно-емкостную характеристику, связанную с наличием пустот различного типа, а также высокие значения газосодержания пластовой нефти. Для поддержания производительности на высоком уровне необходимо для каждой конкретной скважины 
подбирать свое забойное давление, а для этого должен быть известен показатель снижения продуктивности, который определяется путем проведения гидродинамических исследований $[23,24]$.

Показатель снижения продуктивности $(a)$ добывающей скважины по нефти

$$
a=\frac{1}{P_{\text {заб1 }}-P_{\text {заб } 2}} \operatorname{Ln} \frac{K_{\text {прод1 }}}{K_{\text {прод2 }}},
$$

где $K_{\text {прод1 }}-$ коэффициент продуктивности при забойном давлении $P_{\text {заб1 }} ; K_{\text {прод2 }}-$ коэффициент продуктивности при забойном давлении $P_{\text {заб2 }}$.

В зарубежной литературе [25-31] для характеристики интенсивности трещиноватости используется параметр $\beta$, который изменяется от нескольких сотен и более в случае сильно трещиноватых коллекторов до значений, равных или несколько меньших единицы в случае поровых коллекторов, при этом

$$
\beta=\frac{K_{\text {гди }}}{K_{\text {керн }}},
$$

где $K_{\text {гди }}$ - проницаемость, определенная по данным гидродинамических исследований скважин (КВД); $K_{\text {керн }}$ - проницаемость матрицы, определенная по керну.

На рис. 5 представлены зависимости показателя снижения продуктивности от параметра интенсивности трещиноватости для различных зон карбонатного коллектора Гагаринского и Озерного месторождений.

При обработке промысловых данных получены зависимости для оценки показателя снижения продуктивности при изменении забойных давлений для зон с различным типом коллектора:

а) зоны, обладающие открытой естественной трещиноватостью:

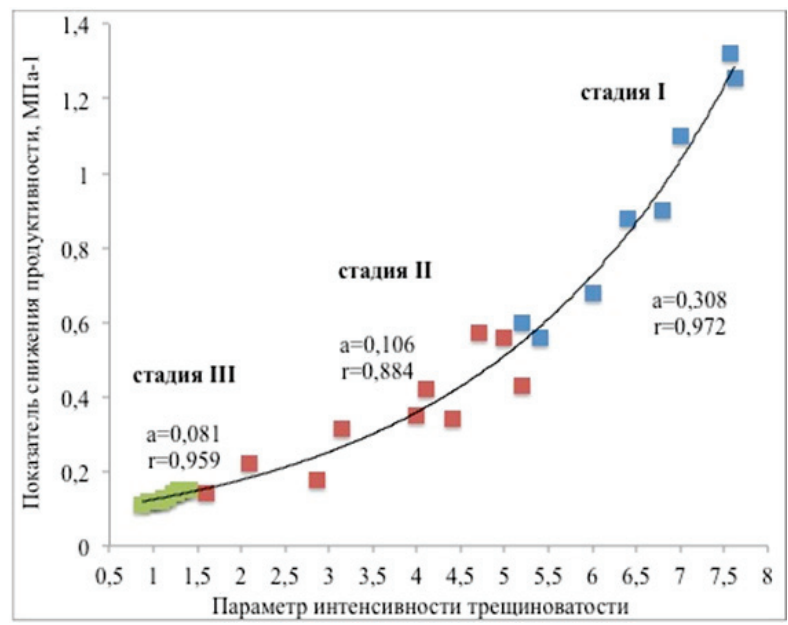

$$
a / a
$$

$$
\begin{aligned}
& a=0,308 \beta-1,093 \text { при } 5,1<\beta<8,0 ; \\
& a=0,106 \beta-0,042 \text { при } 1,52<\beta<5,0 ; \\
& a=0,081 \beta+0,041 \text { при } 0,8<\beta<1,5 ;
\end{aligned}
$$

б) зоны, обладающие естественной трещиноватостью, частично залеченной вторичными минералами:

$$
a=0,0799 \beta+0,04 \text { при } \beta<1,5 ;
$$

Установлено, что основным фактором, влияющим на продуктивность скважин, является деформация коллекторов при снижении пластовых и забойных давлений. Анализ данных гидродинамических исследований и геологических особенностей строения позволяет определить забойное давление для каждой добывающей скважины.

\section{Заключение}

Таким образом, карбонатные коллекторы турнейско-фаменских отложений Гагаринского и Озерного месторождений характеризуются двумя типами коллекторов: один характеризуется как трещинно-поровый, обладающий в исходном состоянии открытой естественной трещиноватостью, второй - как трещинно-поровый, обладающий естественной трещиноватостью, частично залеченной вторичными минералами, переходящий в поровый. Скважины, находящиеся в зоне верхнего тылового шлейфа, имеют многократное снижение продуктивности при снижении пластового и забойного давлений; скважины, расположенные в зонах биогермного ядра, нижнего тылового шлейфа и рифового склона, характеризуются более медленным и монотонным снижением продуктивности.

В данной работе получена система эмпирических зависимостей для оперативной оценки и прогнозирования параметров естественной трещиноватости и коэффициентов продуктивности сква-

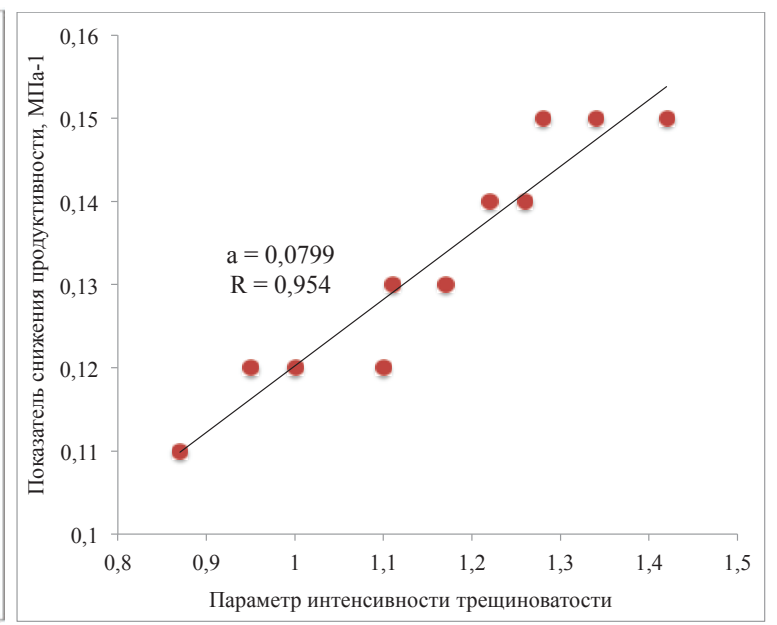

$\sigma / b$

Pис. 5. Зависимость показателя снижения продуктивности от паралетра интенсивности трещиноватости для зон коллектора: а) с открытой естественной трещиноватостью; б) с естественной трещиноватостью, частично залеченной вторичныли минералами

Fig. 5. Dependence of the productivity decline index on fracture intensity parameter for the collector zone: a) with open natural fracturing; б) with natural fracturing, partially healed by secondary mineral 
жин, основанная на промысловых данных. С помощью полученных зависимостей можно оценить и прогнозировать среднюю раскрытость трещин, коэффициенты перетока, относительную емкость естественных трещин, а также продуктивность

\section{СПИСОК ЛИТЕРАТУРЫ}

1. Анализ эффективности вскрытия трещинных и трещинно-поровых карбонатных коллекторов турнейско-фаменского комплекса на нефтяных месторождениях Соликамской депрессии: отчет о научно-исследовательской работе / руководитель В.Д. Викторин. - Пермь: Изд-во 000 «Нефртегазсервис», 2001. - 150 с.

2. Денк С.0. Коллекторские свойства и вопросы разработки нефтеносных рифовых толщ Приуралья. - Пермь: Изд-во Пермского гос. техн. ун-та, 1997. - 324 с.

3. Денк С.0. Нетипичные продуктивные объекты Пермского Предуралья. - Пермь: ПермНИПИнефть, 1997. - 328 с.

4. Путилов И.С. Разработка технологий комплексного изучения геологического строения и размещения месторождений нефти и газа. - Пермь: Изд-во Пермского национального исследовательского политехнического университета, 2014. - 285 с.

5. Применение метода рентгеновской томографии при петрофизических исследованиях керна нефтяных и газовых месторождений / С.В. Галкин, А.А. Ефимов, С.Н. Кривощеков, Я.В. Савицкий, С.С. Черепанов // Геология и геофизика. - 2015. T. 56. - № 5. - С. 995-1007.

6. Опыт исследования керна карбонатных отложений методом рентгеновской томографии / А.А. Ефимов, Я.В. Савицкий, С.В. Галкин, С. Шапиро // Вестник Пермского национального исследовательского политехнического университета. Геология. Нефтегазовое и горное дело. - 2016. - № 18. - С. 23-32.

7. Савицкий Я.В. Современные возможности метода рентгеновской томографии при исследовании керна нефтяных и газовых месторождений // Вестник Пермского национального исследовательского политехнического университета. Геология. Нефтегазовое и горное дело. - 2015. - № 15. - С. 28-37.

8. Гладков Е.А. 0 полигенной природе формирования углеводородсодержащих трещиновато-кавернозных карбонатных коллекторов // Бурение и нефть. - 2011. - № 10. - С. 16-19.

9. Экспериментально-аналитические исследования изменения трещинной проницаемости вследствие смыкания трещин / Ю.А. Кашников, С.Г. Ашихмин, Д.В. Шустов, А.А. Антоненко, Н.Б. Красильникова // Нефтяное хозяйство. - 2013. № 4. - С. 40-43.

10. Наказная Л.Г. Фильтрация жидкости и газа в трещиноватых коллекторах. - М.: Недра, 1972. - 184 с.

11. P-wave velocity anisotropy related to sealed fractures reactivation tracing the structural diagenesis in carbonates / C. Matonti, Y. Guglielmi, S. Viseur, S. Garambois, L. Marié. Tectonophysics. - 2017. - № 705. - P. 80-92.

12. Храмченков М.Г., Королев Э.А. Динамика развития трещин в нефтенасыщенных карбонатных пластах башкирского яруса Республики Татарстан // Нефтяное хозяйство. - 2017. № 4. - C. 54-57.

13. Structural diagenesis in carbonate fault damage zone: a case study of the No.1 fault zone in the Tarim basin Yanshi Xuebao L.J. Znang, G.H. Wu, S. He, Z.C. She, Y.Y. Pan // Acta Petrologica Sinica. - 2016. - № 32 (3). - P. 922-934.

14. Flexural fracture response of a novel iron carbonate matrix - glass fiber composite and its comparison to portland cement-based composites / S. Das, A. Hendrix, D. Stone, N. Neithalath // Construction and Building Materials. - 2015. - № 93. - P. 360-370.

15. Руководство по исследованию скважин / А.И. Гриценко, 3.С. Алиев, 0.М. Ермилов, В.В. Ремизов, Г.А. Зотов. - М.: Наука, 1995. - 523 с. скважин при изменении забойного давления как для вновь пробуренных добывающих скважина на Гагаринском и Озерном месторождениях, так и для вновь осваиваемых нефтяных месторождений, находящихся на территории Верхнего Прикамья.

16. Орехов А.Н., Амани Мангуа М.М. Информативность геометрических атрибутов для прогнозирования трещиноватости коллекторов на примере месторождения углеводородов Томской области // Известия Томского политехнического университета. Инжиниринг георесурсов. - 2019. - Т. 330. - № 9. C. $230-238$.

17. Bourdet D. Well test analysis: the use of advanced interpretation models. - Amsterdam: Elsevier Science, 2002 - 438 p.

18. Черепанов С.С. Комплексное изучение трещиноватости карбонатных залежей методом Уоррена-Рута с использованием данных сейсмофациального анализа (на примере турне-фаменской залежи Озерного месторождения) // Вестник Пермского национального исследовательского политехнического университета. Геология. Нефтегазовое и горное дело. - 2015. № 14. - C. 6-12.

19. Определение параметров трещиноватости пород на основе комплексного анализа данных изучения керна, гидродинамических и геофизических исследований скважин / С.С. Черепанов, И.Н. Пономарева, А.А. Ерофеев, С.В. Галкин // Нефтяное хозяйство. - 2014. - № 2. - С. 94-96.

20. Мордвинов В.А., Мартюшев Д.А., Пузиков В.И. Оценка влияния естественной трещиноватости коллектора на динамику продуктивности добывающих скважин сложнопостроенной нефтяной залежи // Нефтяное хозяйство. - 2014. - № 11. C. $120-122$

21. Natural fracture characterization in aptian carbonates, Araripe Basin / T.S. Miranda, J.A. Barbosa, J.F.W. Gale, 0.J. Correia, M.L. Alencar / NE Brazil $76^{\text {th }}$ European Association of Geoscientists and Engineers Conference and Exhibition 2014: Experience the Energy - Incorporating SPE EUROPEC. - Amsterdam, Netherlands, 2014. - P. 1671-1675.

22. Comprehensive multiple fracture pressure analysis tests to appraise and develop unconventional organic-rich carbonaceous shales in North Kuwait / E. Fidan, C. Darous, T. Bloushi, Q.M. Dashti, M.D. Al-Mutairi // Society of Petroleum Engineers - SPE Hydraulic Fracturing Technology Conference. - The Woodlands, Texas, USA, 2014. - P. 121-133.

23. Бегма Д.С., Белкина В.А. Литолого-фациальные особенности строения верхнеюрских отложений месторождения Т // Известия Томского политехнического университета. Инжиниринг георесурсов. - 2017. - Т. 328. - № 1. - С. 109-122.

24. Исаева 0.А., Чернышов А.И. Литолого-петрографические особенности и коллекторские свойства пород горизонта AB1 ЛасЕганского нефтяного месторождения // Известия Томского политехнического университета. Инжиниринг георесурсов. 2016. - T. 327. - № 7. - C. 6-12.

25. Reiss L.H. The reservoir engineering aspects of fractured formations. - Paris: Institut francais du petrole, 1980. - $110 \mathrm{p}$.

26. Achinta Bera, Hadi Belhaj. A comprehensive review on characterization and modeling of thick capillary transition zones in carbonate reservoirs // Journal of Unconventional Oil and Gas Resources. - December 2016. - V. 16. - P. 76-89.

27. Rock-physics-model-based pore type characterization and its implication for porosity and permeability qualification in a deeplyburied carbonate reservoir, Changxing formation, Lower Permian, Sichuan Bain / X. Jin, Q. Dou, J. Hou, Q. Huang, Y. Sun, Y. Jiang, T. Li, P. Sun, Ch. Sullivan, H. Adersokan, Zh. Zhang // China Journal of Petroleum Science and Engineering. - May 2017. - V. 153. - P. 223-233. 
28. Hosa A., Wood R. Quantifying the impact of early calcite cementation on the reservoir quality of carbonate rocks: a 3D processbased model // Advances in Water Resources. - June 2017. V. $104 .-$ P. $89-104$.

29. Menke H.P., Bijeljic B., Blunt M.J. Dynamic reservoir -condition microtomography of reactive transport in complex carbonates: effect of initial pore structure and initial brine $\mathrm{pH} / /$ Geochimica et Cosmochimica Acta. - 1 May 2017. - V. 204. - P. 267-285.
30. Khanna A., Neto L.B., Kotousov A. Effect of residual opening on the inflow performance of a hydraulic fracture // International Journal of Engineering Science. - 2014. - № 74. - P. 80-90.

31. Bortolan Neto L., Kotousov A. Residual opening of hydraulic fractures filled with compressible proppant // International Journal of Rock Mechanics and Mining Sciences. - 2013. № 61. - P. 223-230.

Поступила 15.12 .2018 г.

\section{Информация об авторах}

Мартюшев Д.А., кандидат технических наук, доцент кафедры нефтегазовых технологий Пермского национального исследовательского политехнического университета.

Зайщев P.A., инженер 1-й категории управления проектирования и мониторинга разработки филиала 000 «ЛУКОЙЛ-Инжиниринг» «ПермНИПИнефть» в г. Перми. 
UDC 622.276

\title{
INFLUENCE OF OIL FIELD REEF CARBONATE RESERVOIR PETROPHYSICAL PARAMETERS OF TOURNASIAN-FAMENNIAN DEPOSITS IN UPPER KAMA ON WELL PRODUCTIVITY
}

\author{
Dmitry A. Martyushev', \\ martyushevd@inbox.ru \\ Roman A. Zaytsev \\ roman.zaitsev@pnn.lukoil.com \\ 1 Perm National Research Polytechnic University, \\ 29, Komsomolskiy avenue, Perm, 614990, Russia. \\ 2 Branch of 000 «LUKOIL-Engineering» «PermNIPIneft» in Perm, \\ 29, Sovetskoy armii street, Perm, 614000, Russia.
}

The relevance of the discussed issue is caused by the fact that the majority of carbonate deposits of the Upper Kama region oil deposits confined to reef structures belong to the fissure-pore type reservoirs. When exploring such complex objects, the productivity of the wells depends on the openness and permeability of fractures, their relative capacitance and mutual interrelation between fractures and matrix, on azimuthal spread of natural fractures in the area of the deposits. These parameters and factors are differently manifested in separate sections of the deposits in the course of their development and, in this relation, the issue of estimating and predicting the productivity coefficients of production wells in development of oil fields of the Upper Kama region is one of the topical and priority.

The main aim of the study is to obtain empirical dependencies for operational prediction of natural fracturing parameters and productivity of producing wells on commercial data.

Objects: Tourney-Famennian carbonate deposits of the Solikamsk depression fields of the Perm region.

Methods. The work is based on literature materials and research of scientists in this field. Studies are based on actual field materials of geophysical, hydrodynamic studies conducted in the oil fields of the Upper Kama region; the data of laboratory studies of core material and rock sections.

Results. The authors have determined the relative capacitive characteristics of the fractures, the coefficients of the flow between the fractures and the matrix, and the average fractures openness, as well as their dynamics with decreasing bottomhole and reservoir pressures during deposits exploration. A system of empirical relationships was developed and justified for estimating and predicting the average openness and relative fractures capacity, the coefficients of flow between the matrix and fractures, as well as the productivity of producing wells in developing oil deposits with carbonate reservoirs.

Key words:

Litho-facies zones, carbonate reservoirs, natural fractures, fracture opening, relative fracture capacity, well productivity.

\section{REFERENCES}

1. Viktorin V.D. Analiz effektivnosti vskryitiya treshchinnykh $i$ treshchinno-porovykh karbonatnykh kollektorov turneysko-famenskogo kompleksa na neftyanykh mestorozhdeniyakh Solikam skoy depressii: otchet o nauchno-issledovatelskoy rabote [Analysis of the effectiveness of the opening of fractured and fissured-porous carbonate reservoirs of the Tournaisian-Famennian complex at the oil fields of the Solikamsk depression]. Perm, Neftegazservis LLC Publ., 2001. 150 p.

2. Denk S.0. Kollektorskie svoystva i voprosy razrabotki neftenosnykh rifouykh tolshch Priuralya [Collector properties and issues of development of oil-bearing reef strata of the Urals]. Perm, State Technical University Publ., 1997. 324 p.

3. Denk S.0. Netipichnye produktivnye obekty Permskogo Preduralya [Untypical productive objects of the Perm Ural region]. Perm, PermNIPIneft Publ., 1997. 328 p.

4. Putilov I.S. Razrabotka tekhnologiy kompleksnogo izucheniya geologicheskogo stroeniya i razmeshcheniya mestorozhdeniy nefti $i$ gaza [Development of technologies for a comprehensive study of the geological structure and location of oil and gas fields]. Perm, Perm National Research Polytechnic University Publ. house, 2014. $285 \mathrm{p}$.

5. Galkin S.V., Efimov A.A., Krivoshchekov S.N., Savitsky Ya.V., Cherepanov S.S. Application of the X-ray tomography method in petrophysical studies of the core of oil and gas deposits. Geology and geophysics, 2015, vol. 56, no. 5, pp. 995-1007. In Rus.
6. Efimov A.A., Savitsky Ya.V., Galkin S.V., Shapiro S. Experience in the study of the core of carbonate deposits by the X-ray tomography method. Bulletin of the Perm National Research Polytechnic University. Geology. Oil and gas and mining, 2016, no. 18, pp. 23-32. In Rus.

7. Savitsky Ya.V. Modern possibilities of the method of X-ray tomography in the study of the core of oil and gas deposits. Bulletin of the Perm National Research Polytechnic University. Geology. Oil and gas and mining, 2015, no. 15, pp. 28-37. In Rus.

8. Gladkov E.A. On the polygenic nature of the formation of hydrocarbon-containing fractured-cavernous carbonate reservoirs. Drilling and oil, 2011, no.10, pp. 16-19. In Rus.

9. Kashnikov Yu.A., Ashikhmin S.G., Shustov D.V., Antonenko A.A., Krasilnikova N.B. Experimental and analytical studies of the change in fracture permeability due to the closing of cracks. Oil Industry, 2013, no. 4, pp. 40-43. In Rus.

10. Nakaznaya L.G. Filtratsiya zhidkosti $i$ gaza $v$ treshchinovatykh kollektorakh [Filtration of liquid and gas in fractured reservoirs]. Moscow, Nedra Publ., 1972. 184 p.

11. Matonti C., Guglielmi Y., Viseur S., Garambois S., Marié L. P-wave velocity anisotropy related to sealed fractures reactivation tracing the structural diagenesis in carbonates. Tectonophysics, 2017, no. 705, pp. 80-92.

12. Khramchenkov M.G., Korolev E.A. Dynamics of fracture growth in oil saturated carbonate beds of the Republic of Tatarstan. Oil Industry, 2017, no. 1, pp. 54-57. In Rus. 
13. Zhang L., Wu G.H., He S., She Z.C., Pan Y.Y. Structural diagenesis in carbonate fault damage zone: A case study of the No. 1 fault zone in the Tarim basin Yanshi Xuebao. Acta Petrologica Sinica, 2016, vol. 32 (3), pp. 922-934.

14. Das S., Hendrix A., Stone D., Neithalath N. Flexural fracture response of a novel iron carbonate matrix - glass fiber composite and its comparison to portland cement-based composites. Construction and Building Materials, 2015, no. 93, pp. 360-370.

15. Gritsenko A.I., Aliev Z.S., Ermilov O.M., Remizov V.V., Zotov G.A. Rukovodstvo po issledovaniyu skvazhin [A guide to well investigation]. Moscow, Nauka Publ., 1995. 523 p.

16. Orekhov A.N., Amani Mangua M.M. Informativeness of geometric attributes for predicting fracture of reservoirs using an example of a hydrocarbon field in the Tomsk Region. Bulletin of the Tomsk Polytechnic University. Geo assets Engineering, 2019, vol. 330, no. 9, pp. 230-238. In Rus.

17. Bourdet D. Well test analysis: the use of advanced interpretation models. Amsterdam, Elsevier Science, 2002. 438 p.

18. Cherepanov S.S. Complex study of the fracturing of carbonate deposits by the method of Warren-Rut using data from seismic facies analysis (on the example of the tour-Famennian deposit of the Ozernoye deposit). Bulletin of the Perm National Research Polytechnic University. Geology. Oil and gas and mining, 2015, no. 14, pp. 6-12. In Rus.

19. Cherepanov S.S., Ponomareva I.N., Erofeev A.A., Galkin S.V. Determination of fracture parameters of rocks on the basis of complex analysis of core data, hydrodynamic and geophysical studies of wells. Oil Industry, 2014, no. 2, pp. 94-96. In Rus.

20. Mordvinov V.A., Martyushev D.A., Puzikov V.I. Evaluation of the effect of the natural fracturing of the reservoir on the dynamics of the productivity of producing wells of a complexly built oil deposit. Oil Industry, 2014, no.11, pp. 120-122. In Rus.

21. Miranda T.S., Barbosa J.A., Gale J.F.W., Correia 0.J., Alencar M.L. Natural fracture characterization in aptian carbonates, Araripe Basin. NE Brazil 76 $6^{\text {th }}$ European Association of Geoscientists and Engineers Conference and Exhibition 2014: Experience the Energy - Incorporating SPE EUROPEC 2014. Amsterdam, Netherlands, 2014. pp. 1671-1675.

22. Fidan E., Darous C., Bloushi T., Dashti Q.M., Al-Mutairi M.D. Comprehensive multiple fracture pressure analysis tests to appraise and develop unconventional organic-rich carbonaceous shales in North Kuwait. Society of Petroleum Engineers - SPE Hydraulic Fracturing Technology Conference. The Woodlands, Texas, USA, 2014. pp. 121-133.

23. Begma D.S., Belkina V.A. Lithological and facial features of the structure of the Upper Jurassic deposits T. Bulletin of the Tomsk Polytechnic University. Geo assets Engineering, 2017, vol. 328, no. 1, pp. 109-122. In Rus.

24. Isaeva O.A., Chernyshov A.I. Lithologo-petrographic features and reservoir properties of rocks of the horizon AB1 of the LasEgansk oil field. Bulletin of the Tomsk Polytechnic University. Geo Assets Engineering, 2016, vol. 327, no. 7, pp. 6-12. In Rus.

25. Reiss L.H. The reservoir engineering aspects of fractured formations. Paris, Institut francais du petrole, $1980.110 \mathrm{p}$.

26. Achinta Bera, Hadi Belhaj. A comprehensive review on characterization and modelong of thick capillary transition zones in carbonate reservoirs. Journal of Unconventional Oil and Gas Resources, December 2016, vol. 16, pp. 76-89.

27. Jin X., Dou Q., Hou J., Huang Q., Sun Y., Jiang Y., Li T., Sun P., Sullivan Ch., Adersokan H., Zhang Zh. Rock-physics-model-based pore type characterization and its implication for porosity and permeability qualification in a deeply-buried carbonate reservoir, Changxing formation, Lower Permian, Sichuan Bain. China Journal of Petroleum Science and Engineering, May 2017, vol. 153 , pp. 223-233.

28. Hosa A., Wood R. Quantifying the impact of early calcite cementation on the reservoir quality of carbonate rocks: a 3D processbased model. Advances in Water Resources, June 2017, vol. 104, pp. 89-104.

29. Menke H.P., Bijeljic B., Blunt M.J. Dynamic reservoir -condition microtomography of reactive transport in complex carbonates: effect of initial pore structure and initial brine $\mathrm{pH}$. Geochimica et Cosmochimica Acta, 1 May 2017, vol. 204, pp. 267-285.

30. Khanna A., Neto L.B., Kotousov A. Effect of residual opening on the inflow performance of a hydraulic fracture. International Journal of Engineering Science, 2014, no. 74, pp. 80-90.

31. Bortolan Neto L., Kotousov A. Residual opening of hydraulic fractures filled with compressible proppant. International Journal of Rock Mechanics and Mining Sciences, 2013, no. 61, pp. 223-230.

Received: 15 December 2018.

\section{Information about the authors}

Dmitry A. Martyushev, Cand Sc., associate professor, Perm National Research Polytechnic University.

Roman A. Zaytsev, engineer of the $1^{\text {st }}$ category, branch of 000 «LUKOIL-Engineering» "PermNIPIneft» in Perm. 